\title{
THE PRINCIPALS' PERCEPTION OF THEIR VALUES AND THE ORGANIZATIONAL CULTURE OF THE JUNIOR HIGH SCHOOLS IN THE DRUZE SECTOR
}

\author{
Nabila KHEIR-FADDUL ${ }^{1}$ \\ Nicolae BIBU ${ }^{2}$ \\ Marian NASTASE ${ }^{3}$
}

\begin{abstract}
The paper deals with a study concerning the principals' perceptions of their values and the type of organizational culture that exist in their schools in the Druze sector. A research was conducted with six Druze principals in Junior High schools in Northern Israel, under the form of interviews. Parallel to the interviews, the OCAI questionnaire was distributed to the teachers, employees and principals to find out the organizational culture in the schools. The results of the OCAI questionnaires show that the clan culture is the most dominant one, the market culture is the second and the adhocracy culture is the third. The results of the interviews show that the principals work on two kinds of values: the Druze values: telling the truth, saving the traditions and the honor and dignity of others. And the universal values: respect, order, loyalty, inclusion and understanding others, fairness, flexibility, belonging, commitment, conscience, consistency, forgiveness, honesty, telling the truth, professional ethics, responsibility, setting limits, striving for excellence, teamwork, tolerance, trust, good intention, the ability to give, the equation between giving and taking, affiliation and the importance of the group. The values of the principals can predict the organizational culture and vice versa. The intended contribution of the research is to raise the awareness of the principal and the teachers to the values of the principals and to the organizational culture, and to think of ways to improve them. The intended contribution of this research to the science is to give more evidence to the correlation between the dominant organizational culture and the principals' values where one can be predicted by the other.
\end{abstract}

Keywords: Druze sector, OCAI instrument, organizational culture, principals' values

JEL classification: I21

DOI: $10.24818 /$ RMCI.2019.3.210

${ }^{1}$ Nabila KHEIR-FADDUL, E-mail: nabila.fadul@gmail.com

${ }^{2}$ Bibu Nicolae, West University of Timisoara, Romania, E-mail: nicubibu@yahoo.com

${ }^{3}$ Nastase Marian, Bucharest University of Economic Studies, Romania, E-mail:

nastasemarian@yahoo.com 


\section{The Druze Community}

Druze people are a religious group of people that started in Egypt in the eleventh century. There are more than a million and a half Druze people in the world. They live mainly in Israel, Syria, and Lebanon. Their religion is secret (Hirsch and Cicurel, 2010). There are about 120,000 Druze residents in Israel. They live mainly in three areas: in twelve villages in the north of Israel, in two villages in the Carmel Mountain and four villages in the Hormone Mountain. In Israel nowadays there are about 30,000 Druze students who study from kindergartens till the universities.

The Druze society has its own beliefs, culture, traditions, values, and virtues (Falah, 2018). Druze people must save the following three values: the religion, the land, and the honor and dignity of the Druze people wherever they are. The Druze people have the following seven virtues: believe in God, unify Him, tell the truth in order to realize the justice, satisfaction, acceptance of the decisions of Gods; save the brothers (all the Druze people all over the world are called the brothers), and love the brothers.

The following characteristics are of a fundamental value in the Druze religion: generosity, courage, protection of the intruder, honesty, participation in weddings and funerals, visiting the sick people, helping the weak, fairness, loyalty, forgiveness, patience, and respect the parents. It is true that the Druze people keep and maintain their culture, traditions, and values. However, being exposed to other cultures, they changed in certain cases (Falah, 2018).

\section{Defining the organizational culture}

The organizational culture is a very wide concept. It was used for almost 40 years. Through these years people understood it in many different ways. That is why it gained many definitions. Costa 2003 (as cited by Serpa, 2016, p. 56). "Organizational culture may be considered as the shared way of being, thinking and acting in a collective of coordinated people with reciprocal expectations; it is shaped, disseminated, learned and changed over time, providing some predictability in every organization." (Serpa , 2016). "Organizational culture is the shared values, beliefs, and norms that influence the way employees think, feel and behave toward each other and toward people outside the organization" (George and Jones, 2008). "Organizational culture is a system of values held and conducted by members of an organization which distinguishes the organization from other organizations" (McBain, 2007).

The organizational culture indicates which beliefs and behaviors are acceptable and supported to be in the organization and which are not (Dyck and Neubert, 2007). The organizational culture is significant that if two different organizations share the same organizational culture, they work together efficiently. If the cultural factor and the values of the employees in Intercultural Virtual Work Teams are closer, the possibility that the work will succeed is higher. University

Review of International Comparative Management

Volume 20, Issue 3, July 2019 
Professors Bibu and Haş (2011) found out that Intercultural Virtual Work Teams can be efficiently managed by the comprehension of the significance of the cultural background and its influence on personal values, emotions, and human behaviors. The organizations and people can have many benefits by being aware of some differences, but also similarities in their cultures and taking advantage of this diversity!

Strong organizational culture can help in achieving cohesion. Cohesion is defined in Longman Dictionary, 1995 (as cited by university professors Nicolae Bibu and Laura Brancu, 2008) as "The act or process of holding together firmly as parts of the same mass, of adhering one to each other, and of becoming united in ideas or interests." Shared ideas, values, purpose, and meaning are things that can help in achieving cohesion. "More cohesion means a stronger link between components of the system that is more bonding, increased stickiness, less heterogeneity." (Bibu and Brancu, 2008). The Druze people have stuck together for a thousand year without having a country of their own. One of the things that helped the Druze people to stick together is their doctrine and culture which make the Druze people follow shared ideas, values, and purpose (Hirsch and Cicurel, 2010). The researcher argues that the Druze schools which are part of the whole Druze sector also share specific values that specializes them from others.

Costa 2003 (as cited by Serpa, 2016, p. 56) wrote about three levels of components that can express all the constituents of the organizational culture. The first level is the "artifacts" which is the "physical space, material objects, arrangements, technologies, written and spoken language, anecdotes, metaphors, stories, myths, artistic productions, rituals, ceremonies, heroes, historical remains, traditions, symbols, habits, rules and standards, patterns of behavior." The second level is the "values". This level expresses the "values and beliefs, attitudes, organizational ethics, ideologies, justifications for action, knowledge, intentions, vision and mission, feelings." The third level is the "key assumptions" which are the "set of assumptions taken as true, invincible, internalized in individuals that are expressed in the conceptions about the relations with the environment (domination, submission, harmonization), of the nature of reality (real, unreal, facts) and the truth (revealed, discovered), of human nature (good, bad, perfection), of the nature of human activity (activity, passivity, work, leisure) and of the nature of human relationships (cooperation, competition, individualism, power, love)".

For the purpose of finding out the organizational culture of the schools, the OCAI instrument was used. The OCAI is an instrument that helps to discover the organizational culture. It is composed of four types of cultures: the clan culture, the adhocracy culture, the market culture, and the hierarchy culture (Cameron \& Quinn, 2011). The clan culture is "a very friendly place to work where people share a lot of themselves. It is like an extended family. The leaders 'are considered to be mentors and, maybe even, parent figures. The organization is held together by loyalty or tradition .Commitment is high. The organization emphasizes the longterm benefit of human resource development and attaches great importance to cohesion and morale. Success is defined in terms of sensitivity to customers and concern for people. The organization places a premium on teamwork, participation,

212 Volume 20, Issue 3, July $2019 \quad$ Review of International Comparative Management 
and consensus." (Cameron \& Quinn, 2011, P. 11). In the market culture, people are competitive and goal oriented. The leaders are hard drivers, producers, and competitors. The glue that holds the organization together is an emphasis on winning. The adhocracy culture is a dynamic, entrepreneurial, and creative place to work. The leaders are considered to be innovators and risk takers. The organization's long-term emphasis is on growth and acquiring new resources. The organization encourages individual initiative and freedom. The hierarchy culture is a very formalized and structured place to work. Procedures govern what people do. Maintaining a smoothly running organization is most critical. Formal rules and policies hold the organization together. The long-term concern is on stability and performance with efficient, smooth operations (Cameron \& Quinn, 2011, p. 75).

"Values are used to characterize the organizational culture, societies, and individuals, to trace change over time, and to explain the motivational bases of attitudes and behavior" (Schwartz, 2012). George and Jones (2008) defined values as "one's personal convictions about what one should strive for in life and how one should behave, general criteria, standards, or guiding principles that people use to determine which types of behaviors, events, situations, and outcomes are desirable or undesirable." They also define work values as "an employee's personal convictions about what outcomes one should expect from work and how one should behave at work."

Values point to the beliefs, the thoughts and the directions in the organization. That is why values are considered as the central concept to evaluate the behavior of employees in an organization. (George and Jones, 2008). The employees receive their values from the continuous social interaction; when an organization adopts specific values such as following the rules and caring for the clients and improving the Work performance, then the organizational culture and the results of the work will be different from an organization that does not adopt these values. (Schwartz, 2012).

Each person has many values; however, the importance of each value for the person is different. Also, the importance of the values differs from a person to the other. A particular value may be of great importance for one person, but not significant for another. Prof. Dr./ Shalom Schwartz has developed a group culture model or the Theory of Basic Human Values (Schwartz, 1992; Schwartz, 1994, Schwartz. 2012). It contains ten universal values which are categorized in two dimensions or four higher order value types. The first dimension is Openness to Change (including self-direction and stimulation) vs. Conservation (tradition, conformity, security); while the second dimension is Self-Enhancement (Hedonism, power, and achievement) vs. Self-Transcendence (universalism, benevolence). The actions that are taken in the pursuit of each value type have psychological, practical, and social consequences that may be compatible or may conflict with the pursuit of other value types. For example, actions intended to express obedience (restrictive conformity) are likely to conflict with actions in pursuit of independence (self-direction), but they are compatible with actions promoting social order (security)." 


\section{The influence of the leaders on the organizational culture}

The leaders and the organizational culture are reciprocally connected. The leadership style is reflected in the organizational culture. It affects the whole organizational culture including the teachers' activities and productivity (Mendel, Watson, and McGregor, 2002). "The personalities and talents of the leaders are reflected in the organizational culture. Influential, successful leaders uncover the cultural indicators such as values and assumptions and make conscious decisions about which ones to strengthen and which ones to weaken" (Bass, 1985). The principals have a significant role in changing the organizational culture. Finnigan (2012) cited Rosenholtz who suggested that "principals have a crucial role in changing teachers' beliefs such as the belief that students can learn better and that teachers can improve the performance of the students." Finnigan (2012) also cited Owens who suggested that developing a vision is very crucial for creating shared beliefs and values. The leadership style that the leader chooses to lead the organization accordingly, influences the culture of the organization (Bass, 1985). When principals lead by example and make sure to create positive culture, values, trust, a shared vision, and relationships, teachers will be more satisfied with their jobs (Beauchamp and Parsons, 2012; Herbert, 2011). As it seems, the school organizational culture - as the case in any other organization- is essential for achieving the goals of the schools, and it is essential that it is planned and cared for. "The image or reputation of the organization and organizational culture must be assessed, controlled and directed towards achieving goals" (Bibu and Lavinia, 2012). Somebody needs to take responsibility for constructing a healthy encouraging organizational culture. According to the literature, it is the responsibility of the leaders to improve the organizational culture and making it shared among the staff (Bredeson, 1989). "A school is considered to be successful when the principal is focused on creating an organizational culture conducive to that success" (MacNeil et al., 2009).

It is argued in this research that the organizational culture is of vital importance for schools. It is one of the things that keep the school together and can bring to the desired extent of success. It is essential that the school is aware of its organizational culture. Values however, as it appears in the literature above, are the main feature of the organizational culture. They appear in all the definitions of the organizational culture (Serpa , 2016, George and Jones, 2008, McBain, 2007, Dyck and Neubert, 2007). That is why the principals were asked about their values. Out of the values it was easy to predict the organizational culture.

\section{The OCAI approach}

The OCAI is a practical, efficient, involving manageable, valid and a useful instrument that was used in many studies in education (e.g., Fralinger and Olson, 2007; Kalliath, Bluedorn, and Gillespie, 1999). The OCAI was designed to identify the dominant culture of an organization by profiling that organization

$214 \quad$ Volume 20, Issue 3, July $2019 \quad$ Review of International Comparative Management 
across a quartet of organizational culture types: clan culture, adhocracy culture, market culture, and hierarchy culture (Cameron and Quinn, 2011) The Clan Culture: "A very friendly place to work where people share a lot of themselves. It is like an extended family. The leaders...are considered to be mentors". The Market Culture is "a results-oriented organization. The major concern is getting the job done. People are competitive and goal oriented". The Adhocracy Culture is "a dynamic, entrepreneurial, and creative place to work". The Hierarchy Culture is "a very formalized and structured place to work. Procedures govern what people do. The leaders pride themselves on being good coordinators and organizers" (Cameron and Quinn 2011, p. 75)

"The quadrants are made by dimensions defined by opposite values that conflict and compete with each other. The internal focus and flexibility values of the upper left quadrant directly compete with values of the lower right quadrant that are externally focused control values. On the other diagonal, the upper right quadrant is made up of externally focused and flexibility based values and directly competes with the lower left quadrant values that emphasize internal and control values. The competing values that make up each quadrant form the basis of the Competing Values Framework." Each quadrant represents basic assumptions and core values in the same way that an organizational culture does. The Competing Values Framework serves as a foundation for assessing an organization's general cultural orientation based on the main culture types delineated by each quadrant." (Fox, 2013).

The OCAI instrument is organized into "Now" and "Preferred" sections. Each of these two sections ("Now" and "Preferred") is formed of 6 items that demand the participants to rate their workplace along six organizational dimensions: (a) dominant characteristics, (b) organizational leadership, (c) management of employees, (d) organizational glue, (e) strategic emphasis, and (f) criteria of success. Each of these six items demands the participants to rank four descriptive statements regarding the applicability of that statement to the participants' workplace. Participants must arrive at a total of 100 points for these four descriptors before moving on to the next question. For example, the first item of the OCAI, Dominant Characteristics, like all the other items, presents the participants with four statements that potentially describe the major facet of their institution's culture:

\section{The methodology}

A qualitative approach was conducted to present the perception of the principals to their values. Data were collected through in-depth; one-on-one audiorecorded interviews. The seniority of these principals is between $28-45$ years in teaching and from $4-18$ years in management. The interviews were conducted in July 2018. The meetings were in the principals' offices. After each meeting, the researcher listened to each recording, copied it in a file, and sent it to each principal separately on the e-mail. Each principal read it and gave the researcher an approval 
to use the information in the research. After that, the data was organized for discussion and analysis. One of the purposes of the meeting swith the principals was to find out the values of the principals. Parallel to the meetings, a survey was made in nine Druze schools including the schools of the interviewed principals in May 2018. Its purpose was to check the organizational culture of the schools. For this purpose, the "Organizational Culture Assessment Instrument" (OCAI), developed by Cameron \& Quinn $(1999,2006,2011)$ was used. The OCAI instrument is organized into "Now" and "Preferred" sections. The "Now" section checks the current culture and the "Preferred" section checks the preferred culture they want it to be in five years. The discussion of the OCAI results, chart 1 and figure 1 show both cultures. However only the "Now" culture is related to in the other parts of this paper. Each of these two sections "Now" and "Preferred" is formed of 6 items that demand the participants to rate their workplace along six organizational dimensions: (a) dominant characteristics, (b) organizational leadership, (c) management of employees, (d) organizational glue, (e) strategic emphasis, and (f) criteria of success. Each of these six items demands the participants to rank four descriptive statements regarding the applicability of that statement to the participants' workplace. Each one of these four statements expresses one of the cultures: the clan, marker, adhocracy and hierarchy. Participants must arrive at a total of 100 points for these four descriptors before moving on to the next question. The sample size for this study consisted of 220 staff members: principals, vices, coordinators, homeroom teachers, counselors, teachers with no other roles, integration teachers, secretaries, librarians and other staff members. The questionnaires were distributed to most of the staff who attended at the days when the researcher went to the schools to distribute the questionnaires. Some employees did not agree to fill it in, others took the questionnaires and did not hand it back. 300 copies were distributed. 220 copies were collected. So, both qualitative and quantitative data were used for the purpose of this study.

\subsection{The results of the OCAI questionnaire}

The results of the questionnaires showed that the clan culture is the current one and the preferred culture in the schools (current Mclan $=27.74$, preferred Mclan $=31.11)$, whereas market $($ current Mmarket $=24.20$ preferred Mmarket $=$ 25.81 ), and adhocracy (current Madhocracy $=24.20$ preferred Madhocracy $=21.74$ ) come next with a very small difference between them which is 0.35 for the advantage of the market. And after that, the last and least culture that appear in the schools is the hierarchy (current Mhierarchy $=23.45$, preferred Mhierarchy= 21.47 ) with a difference of 0.75 point from the current adhocracy. In other words, the clan culture seems to be the most dominant current culture with the difference of 3.19 from the market. As it appears, the other two cultures, the market and adhocracy come second with the differences of a fraction of a number. And the 
hierarchy culture is the least popular culture. The results are summarized in both table 1 and figure 1.

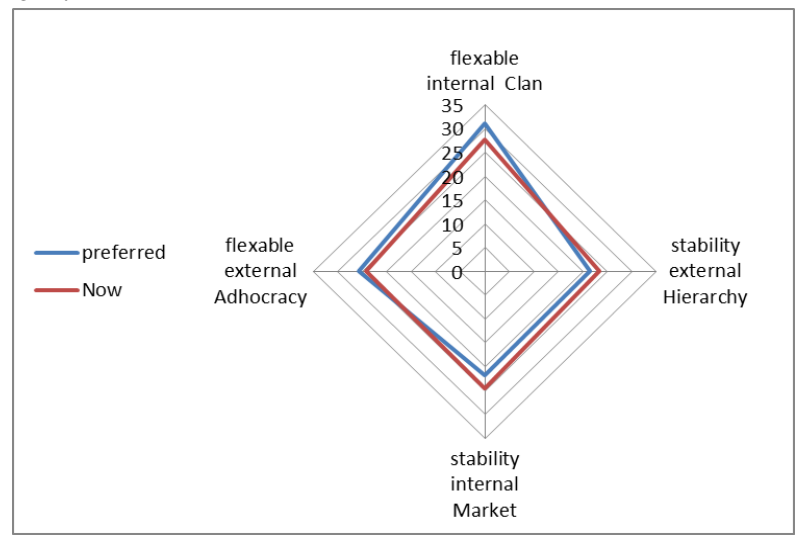

Figure 1: The organizational culture in the Druze sector

Table 1: The organizational culture in the Druze sector

\begin{tabular}{|l|l|l|l|}
\hline & current & Preferred & Difference \\
\hline Clan & 27.74 & 31.11 & 3.37 \\
\hline Adhocracy & 24.20 & 25.81 & 1.61 \\
\hline Market & 24.55 & 21.74 & -2.81 \\
\hline Hierarchy & 23.46 & 21.47 & -1.98914 \\
\hline & 100 & 100 & \\
\hline
\end{tabular}

\subsection{The principals' values}

The principals reported about two kinds of values that they work on: the Druze values and the universal values. The Druze values that they work on are: keeping the brothers, telling the truth, saving the traditions and the honor and dignity of others. Concerns the universal values, each principal mentioned most of the following values: respect, order, loyalty, inclusion and understanding others, fairness, flexibility, belonging, commitment, conscience, consistency, forgiveness, honesty, telling the truth, professional ethics, responsibility, setting limits, striving for excellence, teamwork, tolerance, trust, good intention, the ability to give, the equation between giving and taking, affiliation and the importance of the group, making the balance between being friendly and being strict, and widening the horizons. The principals see the school as a big family. They see themselves as mentors for the teachers and the students and feel that they have certain degrees of responsibilities to make others acquire the values they want them to acquire. The principals see that human resource development is a very important thing. The more they work on improving the teachers' strength and knowledge, the better 
success they gain. They believe that the feelings of the teachers and the students are very important. That is why they pay attention to their feelings.

In order to acquire the Druze values, the schools bring religious people to make lectures to the students. Also, together with the Druze religious council, they make activity days. In these days they take the students to the holy places, the religious people make lectures and activities in which they emphasize the Druze values, their importance and the importance of keep following them. They teach them how maintaining these values keep the Druze people more united and save their own uniqueness. It also makes them able to recognize each other wherever they go. The principals see that the Druze values and traditions are very important and it is important to keep and maintain them. They are the things that will keep their cohesion.

Concerns the universal values, mutual respect is one of the most important values all the principals talked about. Respecting all human beings is a very important value that the principals want everybody in the schools to acquire. Some principals reported that because everybody treats other with respect, almost there are no discipline problems. The principals teach the teachers not to challenge the students but to treat them with respect and show them that they are valuable for them. Another value the principals work on is "order". One principal gave an example that our bodies are built in an order which without it people get sick; all the machines have systems and work with order. So do schools. If everybody works with order, organizes his time, thoughts and things, his life will be easy and everybody will be calm because they know what to do. The principals mean order also in the behavior: students have to sit quietly and be disciplined during lessons and learn. Order is also in putting things in their places, to keep the school neat and clean. This way the goals can be achieved easily. The principals said that some schools do not achieve success and the reason is the lack of order. Setting limits is an important value for the principals; it makes things clearer for the teachers and the students. The teachers and the students know their limits and what is allowed and what is not. This brings to a feeling of safety. It brings to more order.

Honesty, conscience and telling the truth are important values for the principals. The principals said that these values bring success and help to achieve the goals of the school. The principals are honest with the teachers and they expect the teachers to be so. One principal mentioned that when the teacher is with his students, nothing is more important than his/her honesty. When the teachers are honest, loyal, work with conscience, and put all their knowledge, power and time in the students, fear and worry diminish. And the students develop and succeed highly. If there is a misunderstanding between two teachers or a teacher and a student, the principals care that the teachers tell the whole truth so that they can help in solving the problem. The principals also make sure to teach these values to the students.

The principals forgive, give more opportunities, and are flexible, but they expect the others to tell them the truth. Flexibility is an important value for the principals. They are flexible and adapt themselves to existing situations and new 
circumstances that are not taken into account. Sometimes they can change the plans if certain things arouse. The principals are aware that when they start the day, they do not know exactly how it will end. They care for explaining this point to the teachers and treat them accordingly. Also, the principal and the teachers explain that to the students. Sometimes the schools postpone important events that the students expect and wait for. They explain to the students why and teach them to be flexible, not get annoyed with that but to direct their thinking towards the substitutes. Another value most of the principals talked about is forgiveness. They reported that they do not keep track on the teachers' mistakes. When teachers make mistakes, the principals treat them with forgiveness and show them the good ways to do things. They try not to criticize them for their mistakes. They know that people do not learn by criticizing. Instead, they learn be encouraging and showing them the ways to think by convincing. The principals see that not giving a comment for every mistake improves the self-confidence of the teachers and helps them improve. The principals see that there is a need sometimes to discard certain things in order for the teachers to prosper and develop in the best ways. Some principals insisted that being modest is one of the most important values that help them succeed in their relationship with the teachers. They said that in order to make others respect them and do what they want: not out of fear but out of respect, they talk to everybody at sight level. They reported that this point brings to better understanding and good relationship in the schools.

The principals work hard to make everybody willing to help others when they need help, to understand them, and see things in their points of view. That is because they believe in the importance of the value of inclusion to the students and to the teachers is one of the most important values for people to acquire. Each of us in a given situation can be the one who needs somebody to absorbed, help and understand him. Today it is possible that $\mathrm{x}$ need the others, tomorrow the others might need $\mathrm{x}$. So there is not a big person and others not. In life everyone needs others.

The principals insisted the importance of taking responsibility. They said that everything is the responsibility of every teacher. Responsibility means and contains a lot of things. The principals feel responsible for providing the teachers and the students with the best circumstances they need, and to have the best school climates that make everybody feel good about the school. They try to provide the schools with the best technology and programs to follow the new changes. The principals said that the teachers have to feel their responsibility for developing themselves and for helping the students to develop their knowledge and skills. The principals also mentioned that all teachers need to feel their responsibility in the school; if teachers pass near students and find that something is not going on well, they have to interfere. The principals are aware that they cannot have control over all the students and the things that happen in the school all alone, but together with the teachers and workers, they can. One value the principals mentioned is "the importance of the group and teamwork". The success of the group is what each one gives it and is reflected on the success of all members. Nobody knows all things. When many people work together, the subject can be covered from many aspects. 
A few principals talked about the importance of Professional ethics. They do not allow gossiping or misunderstanding between teachers. If there is a misunderstanding between teachers, the principals sit with them, let each teacher tell his opinion and make sure to make it up with the teachers. This way there will not be any feeling of resentment. It brings into positive ways of thinking.

Some principals talked about the joy of giving, others talked about the "equation between giving and taking". The principals, who talked about the value of giving, said that they work hard to let the teachers feel the joy in giving without asking for something back. When the principal needs the teachers to do some work, especially when another teacher is absent, the principal can ask without thinking how to reward the teachers. The other principals, who mentioned the equation between giving and taking, believe that if somebody wants something, he/ she has to be willing to give something back. One principal said that if one teacher needs to go home early one day, he has to stay the same time in a different day in the school. One value the principals try to encourage is competing. The principals do not believe that this value is important for itself as a value. They prefer that each teacher teaches using his uniqueness, and each student learn to develop himself properly. However they work on the value of competing because they live in a country where there is competition on the very important jobs. Also, the student achievement is very important. The schools' success is expressed according to the student achievement. That is why they think that competing is an important value to work on. One very important value for the principals is to think and aspire high and to make the teachers and the students aspire for the best.

\subsection{The ways the principals think their values and beliefs are reflected in school}

Most of the principals said that at the beginning, when they were nominated as principals, it took them a lot to make the teachers used to their values. That is because it requires change in their ways of thinking and behaving. However, after being consistent on what they wanted, the teachers changed for good. One principal mentioned that the teachers told him that they started using the values that he wants them to acquire at home. For example, because the principal was very insistent on keeping order, the teachers became very consistent on teaching their children at home to be more organized. The principals mentioned that after the teachers became familiar with their values, things changed for better. One principal reported that the absence of the teachers in his school became less than the half before he became the principal. The principals reported that the schools' environment is better and more comfortable, the teachers come to school with much more enthusiasm and the student achievement is getting higher. Every student knows that everything in the school serves him and serves other. That is why they keep things clean and tidy. Most of the students are polite, they follow the rules. 
The principals could succeed in making everybody acquire their values by being personal examples and by clarifying to the teachers and parents how to be personal examples. The adults are the personal examples of the students, and the principals are the personal examples of teachers and students. A principal has to be attendant and take responsibility if he wants the teachers to take responsibilities; a teacher cannot expect the students to come to school early when they come late. One principal said that because he is a good example, the teachers and the pupils believe in him. People learn from imitating. One principal said that the school stays neat and clean because everybody, including him, if seeing something on the floor they pick it up and throw it in the garbage ban. Another principal said that he acts as a positive personal example for the teachers in concerns absence. He doesn't get absent even if he is sick. The principals build positive organizational culture by strengthening principal-teacher-student relationship, fulfilling the values, not being absent, encouraging, giving certificates, raising the level of awareness of teachers, students and parents.

The principals said that they can help the teachers to acquire their values by constantly reminding them of these values and by talking about them most of the time. Also by implementing them and having these values as a life style. They treat the teachers and the students with good intentions. They are honest, modest, fair, flexible, forgiving and tolerant. The principals set limits, make sure that they have teamwork. Some principals said that they sit with each teacher individually to help them in case and they need help. Some principals reported that they sit almost with all the students in his school, either individually or in small groups, ask them about their needs and how to be successful and about how useful for them is to acquire certain values. They tell the students that their doors are opened for any consulting. They also mentioned that they take responsibility on the things that they are responsible over, and demand everybody to learn to take responsibility for their actions and development. They choose the values that they want to work on and discuss them with the teachers and discuss how they help the students acquire these values. They encourage good deeds not criticize or look for the missing parts in everything. They solve students' discipline problems very carefully and make the students convinced that discipline problems are a negative thing that doesn't help them and they show the students the best ways to behave. One teacher said that she give certificates to the students who are excellent behaviorally.

Some of the points that the principal mentioned that help improving the organizational culture are: strengthening teacher-student relationship, training the educational staff to accompany the students, with emphasis on the planning, implementation, reflection, evaluation and feedback processes. Another thing that can improve the organizational culture is bringing courses and lectures and activities to clarify things and to improve the students' level of awareness and understanding. One principal gave an example about a sex educational week. They brought people to cover the topic in all its aspects and from several points. They invited religious people to explain the point religiously; policemen, to explain how the law protects them sexually; and professionals such as sociologists and 
psychologists. They also covered how to use the internet safely. The students could find experts and people who know to explain to them things they needed explanation about and they got correct answer to their questions. That is better than looking for the information they need in the internet or asking friend who might not have the correct answers.

\section{Discussion}

These principals have a noticeable experience in managing and teaching. The interviews provided a lot of information about the principals' perception of their values and the organizational culture and what they do to generate them, about why they think that their values can bring to higher schools' success. According to the OCAI questionnaire, the school staff rated the clan culture as the dominant culture that they have now. This result is supported by the values that the principals talked about. The principals see themselves as mentors. They see that the teachers and the students have to be committed to the schools' goals. They are loyal to teach the Druze traditions and values. They work hard on the human resource development. They attach great importance to cohesion. They attach great importance for the feeling of the teachers and students and to their morale. These values express the clan culture which is a "very friendly place to work where people share a lot of themselves. It is like an extended family. The leaders are considered to be mentors.... The organization is held together by loyalty or tradition. Commitment is high. The organization emphasizes the long-term benefit of human resource development and attaches great importance to cohesion and morale... The organization places a premium on teamwork, participation, and consensus (Cameron and Quinn, 2011. p. 75).

The second current culture is the market culture. This culture does not appear clear according to the meetings with the principals. According to the market culture, people are supposed to be "competitive and goal oriented. The leaders are hard drivers, producers, and competitors. They are tough and demanding. The glue that holds the organization together is an emphasis on winning. Reputation and success are common concerns" (Cameron and Quinn, 2011. p. 75). Almost none of the things mentioned in the market culture appeared in the interview with the principals apart from the competition. The principals mentioned that the competition is expressed in getting high achievement. The principals mentioned that they encourage competition and getting high achievements because the schools are judged according to the student achievement.

The Adhocracy Culture seems to be the third current culture. According to this culture the workplace is "a dynamic, entrepreneurial, and creative place to work in. The organization's long-term emphasis is on growth and acquiring new resources. The organization encourages individual initiative and freedom" (Cameron and Quinn, 2011.p. 75). The principals mentioned that they encourage creativity, growth and individual initiative and freedom. The principals encourage the teachers to be creative and to think of organizing special activities for the 
schools. They give them lots of freedom to wok. One principal mentioned that he gives certain roles to teachers and give them the freedom to think and bring creative ideas to the schools. Another principal said that some new teachers think of activities for the whole school, that is why he gives them more responsibilities. The principals study the ideas with these teachers and let them make the activities. That brings to greater school success and cohesion.

The hierarchy culture is the least dominant culture according to OCAI. This culture tells that "The leaders are coordinators and organizers... the stability and smooth scheduling formal rules and policies hold the organization together" (Cameron and Quinn, 2011. p. 75). The values of the principals appear to be contradicting to the values that are mentioned on the hierarchy culture. The principals are flexible and organize things that can bring to the benefit of the school. It seems that the result of the OCAI concerns the Hierarchy Culture match the perception of the principals to a certain extent. According to the results of the OCAI, the hierarchy culture is the least dominant culture, but still it exists. According to the interviews, it was not mentioned. It could be that the questions asked did not lead to find it out. The principals should be asked additional questions in order to clarify this point.

The values of the principals were also analyzed according to Schwartz 2012. According to Schwartz there are four higher-order groups of values: openness to change, self-enhancement, conservation, and self-transcendence. The principals seem to have certain values in each group. In the openness to change, the principal believe that it is important for them and for the other teachers to be opened and willing to change, develop, and widen horizons. It is important to striving for excellence and to be flexible. The self-enhancement values that the principals mentioned are the feeling of belonging, commitment, conscience, containing and understanding others; the values that the principals mentioned and that express conservation are: mutual respect, trust, good intention commitment, uniformity, acceptance of the customs and ideas that one's culture or religion provide, keeping the brothers, telling the truth, saving the traditions and the honor and dignity of others. The principals' self-transcendence: understanding, appreciation, tolerance, forgiveness and honesty.

\section{Conclusions}

The results of this study indicate that the junior high school principals have a very strong positive perception of their values and of the ways they implement them. They also have high awareness of the situations in their schools. The results of the OCAI, the literature on the values and the organization culture support the perceptions of the principals. The research results can contribute a lot to the schools that participate in the study. The results are able to provide further evidence of the positive clan culture in the Druze Junior High schools. The information obtained in this study and the values that appear in both the principals' perceptions and the results of the OCAI questionnaires provide the principals and the teachers with a better awareness of the values that operate the schools. The 
results of this study can be guidelines for the teachers to understand how the principals perceive their values and to understand their schools' organizational culture. The results of this study serve as one more evidence that the organizational culture can predict the values of the leaders and vice versa (Mendel et al., 2002). Other principals or schools that need higher success can learn and implement a lot from the things written in this article. Some principals told the researcher that the interviews were very useful, helpful and inspiring for them. They helped them think of new ways and also pay attention to things that they need to work on.

Future research is recommended based on the findings of this study. First, short additional interviews with the principals asking those concerns about the adhocracy culture and how they think it exists (because it exists in the OCAI questionnaires). Second, it is recommended to give the results to the schools to reinforce the positivity, reduce the negativity and guide the principals and the teachers when putting their goals and building programs. Another recommendation is to conduct the same survey in other schools in northern and southern Israel to see if there can be similarities or differences because of the region and the culture.

\section{Bibliography}

1. Bass, B.M. (1985). Leadership and Performance beyond Expectations. New York: The Free Press.

2. Beauchamp, L. \& Parsons, J. (2012). Instructional leadership in alberta: Research insights from five highly effective schools. AASA Journal of Scholarship and Practice, 8(4), 41-50.

3. Bibu, N.A. \& Brancu, L. (2008). Convergences of the Romanian societal culture with European culture clusters in the process of European integration. The role of intercultural teams management in increasing European cohesion.

4. 4. Bibu, N.A. and Haş, D., (2011). A Management Model of Intercultural Virtual Work Teams. Review of International Comparative Management, pp. 83-89

5. Bibu, N.A. and Lavinia, A., (2012). Leadership Style in the Romanian Public Institutions - the Case of City Halls. Review of International Comparative Management. Volume 13, Issue 1, pp. 81-87.

6. Bredeson, P. V. (1989, March). Redefining leadership and the roles of school principals: Responses to changes in the professional work life of teachers. Paper presented at the annual meeting of the American Educational Research Association, San Francisco, CA.

7. Cameron, K. S. \& Quinn, R. E. ( 2011). Diagnosing and Changing Organizational Culture: Based on the Competing Values Framework, 3rd Edition. San Francisco, CA: Jossey-Bass.

8. Cameron, K. S. \& Quinn, R. E. (1999). Diagnosing and changing organizational culture. Reading: Addison-Wesley. 
9. Cameron, K. S. \& Quinn, R. E. (2006). Diagnosing and changing organizational culture: Based on the competing values framework. San Francisco, CA: Jossey-Bass.

10. Dyck, B. \& Neubert, M. J. (2007) Principles of Management. International Student Edition. Library of Congress Control. Printed in China.

11. Falah, J. F. (2018). Does Multicultural Education Affect the Druze Heritage Curriculum? Open Journal of Social Sciences. Vol.06, pp. 257-271.

12. Finnigan, K. S. (2012). Principal leadership in low-performing schools: A closer look through the eyes of teachers. Education and Urban Society, 44(2), pp.183-202. doi:10.1177/0013124511431570.

13. George, J.M., and Jones, G.R. (2008). Understanding and Managing Organizational Behavior (Fifth Edition). Upper Saddle River: New Jersey, Pearson Prentice Hall.

14. Herbert, Elizabeth B. (2011). "The relationship between emotional intelligence, transformational leadership, and effectiveness in school principals". Educational Policy Studies Dissertations, Paper 66.

15. Hirsch, T., \& Cicurel, E. (2010). Identity and belonging as coping resources for Druze adolescents during the Second Lebanon War. Mifgash: Journal of Social-Educational Work. pp. 61-85. Hebrew source.

16. MacNeil, A., Prater, D., \& Busch, S. (2009). The effects of school culture and climate on student achievement. International Journal of Leadership in Education: Theory and practice, 12:1, pp. 73-84.

17. McBain, $\mathrm{R}$ (2007), 'The practice of engagement: research into current employee engagement practice', Strategic $H R$ review, vol 6, no 6, pp 124-136.

18. Mendel, C. M., Watson, R. L., MacGregor, C. J., (2002). A Study of Leadership Behaviors of Elementary Principals Compared With School Climate. Southern Regional Council for Educational Administration.

19. Schwartz, S. H. (2012). An Overview of the Schwartz Theory of Basic Values. Online reading in psychology and culture. International association for Cross-Cultural Psychology.

20. Schwartz, S. H. (1992). Universals in the content and structure of values. Theory and empirical tests in 20 countries. In M. Zanna (Ed.), Advances in experimental social psychology. Vol. 25, pp. 1-65. New York: Academic Press.

21. Schwartz, S. H. (1994). Are there universal aspects in the content and structure of values? Journal of Social Issues, 50, 19-45.

22. Serpa, S. (2016). An Overview of the concept of organisational culture. International Business Management. 10. 51-61. 10.3923/ibm.2016.51.61. 